\title{
Flora da Bahia: Aizoaceae
}

Laura Cristina Pires Lima ${ }^{1 *}$, Reyjane Patrícia de Oliveira ${ }^{1} \&$ Ana Maria Giulietti ${ }^{1,2}$

${ }^{1}$ Programa de Pós-graduação em Botânica, Universidade Estadual de Feira de Santana, Departamento de Ciências Biológicas, Avenida Transnordestina s/n, Novo Horizonte, 44036-900, Feira de Santana, Bahia, Brasil.

${ }^{2}$ Royal Botanic Gardens, TW9 3AB, Richmond, United Kingdom.

\begin{abstract}
Resumo - É apresentado o levantamento florístico de Aizoaceae da Bahia, como contribuição ao conhecimento da flora do Estado. Foram reconhecidas as espécies nativas Sesuvium portulacastrum e Trianthema portulacastrum. É apresentada chave analítica, bem como descrições, ilustrações e comentários gerais sobre os táxons.

Palavras-chave adicionais: Brasil, florística, Sesuvium, Trianthema.
\end{abstract}

\begin{abstract}
Flora of Bahia: Aizoaceae) - This account of the Aizoaceae is a further contribution to the ongoing Flora of Bahia project. Two native species, Sesuvium portulacastrum and Trianthema portulacastum, are recognized for the state of Bahia, Brazil. A key, descriptions, illustrations and general notes on taxa are presented.

Additional key words: Brazil, floristics, Sesuvium, Trianthema.
\end{abstract}

\section{Aizoaceae}

Ervas anuais ou perenes, suculentas. Folhas opostas ou alternas, simples, pouco a extremamente suculentas, pecioladas ou sésseis. Inflorescências cimosas ou frequentemente reduzidas a uma única flor. Flores bissexuadas, raro unissexuadas, hipóginas, períginas ou epíginas, pentâmeras, actinomorfas, monoclamídeas ou diclamídeas; sépalas com apêndice subapical externamente, vistosas ou não, com ou sem estaminódios petaloides internamente, elementos do perianto livres, basalmente conatos ou adnatos aos filetes; estames 4 a numerosos, anteras com deiscência longitudinal; gineceu sincárpico, uni a plurilocular, óvulos 1 a muitos por lóculo, placentação axilar, basal ou parietal. Fruto cápsula loculicida, raramente septicida, geralmente higrocástica, pixídio, noz ou drupa; sementes reniformes, ovoides, pretas ou brancas, com ou sem arilo.

Aizoaceae abrange cerca de 130 gêneros e aproximadamente 2.500 espécies, distribuídas em zonas tropicais e subtropicais de ambos os hemisférios (Hartmann 1993), com centro de diversidade na África do Sul, seguida pela Austrália e Chile (Bittrich \& Hartmann 1989; Short 2011). No Brasil, são nativos os gêneros Sesuvium L. e Trianthema L. (Zappi 2010) e são introduzidos e cultivados Aptenia N.E.Br., Lampranthus N.E.Br., Mesembryanthemum L. e Tetragonia L. (Souza \& Lorenzi 2005). Para o estado da Bahia, foram reconhecidos dois gêneros e duas espécies.

\section{Chave para os gêneros}

1. Folhas lineares ou oblanceoladas; gineceu com 2-5 estiletes; fruto pixídio. 1.1. Sesuvium portulacastrum

1'. Folhas obovadas ou romboidais; gineceu com 1 estilete; fruto noz. 2.1. Trianthema portulacastrum

*Autor para correspondência: lcplima@yahoo.com.br

Editor responsável: Julio Lombardi

Submetido em: 16 ago. 2012; publicação eletrônica: 26 dez. 2012

\section{Sesuvium L.}

Ervas anuais ou perenes, suculentas, às vezes com raízes adventíceas. Folhas opostas, suculentas, papilosas ou glabras. Flores bissexuadas, períginas, solitárias, sésseis ou pediceladas, bractéolas 2 ; sépalas 5 , internamente rosadas ou roxas, margens membranáceas, apêndice unifacial subapical abaxial; estames 5 a numerosos, estaminódios ausentes; ovário súpero, lóculos do ovário e estiletes 2-5, óvulos numerosos por lóculo, placentação axilar. Fruto pixídio; sementes numerosas, pretas, arilo membranáceo ou hialino envolvendo completamente a semente.

O gênero inclui 12 espécies, com registros nas regiões tropicais e subtropicais de todo o mundo, geralmente associadas a ambientes salinos (Bittrich \& Hartmann 1989; Hartmann 1993; Bittrich 2002). No Brasil, está representado por apenas uma espécie (Zappi 2010).

1.1. Sesuvium portulacastrum (L.) L., Syst. Nat., ed. 10: 1058. 1759.

Figuras 1A-E e 2.

Ervas perenes, suculentas, prostradas, ramos quadrangulares em seção transversal, sulcados. Folhas lineares ou oblanceoladas, sésseis, lâmina 1,1-2,4 cm × 1,5-6 $\mathrm{mm}$, ápice subagudo ou obtuso, base alargada formando uma bainha hialina, margem reta, ambas as faces glabras, concolor, crassa, venação hifódroma. Flores com pedicelo 4-9 mm compr., bractéolas 3-4 mm compr., membranáceas, oblongas, ápice agudo, base obtusa, margem reta; sépalas 8-10 mm compr., persistentes, cuculadas, internamente rosadas ou lilás, glabras, margens membranáceas amplas, apêndice linear, ca. $1 \mathrm{~mm}$ compr., agudo; estames 32-38, adnatos às sépalas, estaminódios ausentes, filetes ca. $5 \mathrm{~mm}$ compr., anteras ca. $1 \mathrm{~mm}$ compr.; ovário oval, ca. $3 \mathrm{~mm}$ compr., glabro, lóculos 3, óvulos vários por lóculo, estiletes ca. 3,5 $\mathrm{mm}$ compr., estigma truncado. Pixídio 4-6 × 3,2-3,5 mm compr., oval, glabro; sementes 29-32, ovoides, pretas, arilo membranáceo, superfície lisa.

Sitientibus série Ciências Biológicas 12(2): 189-192. 2012. 


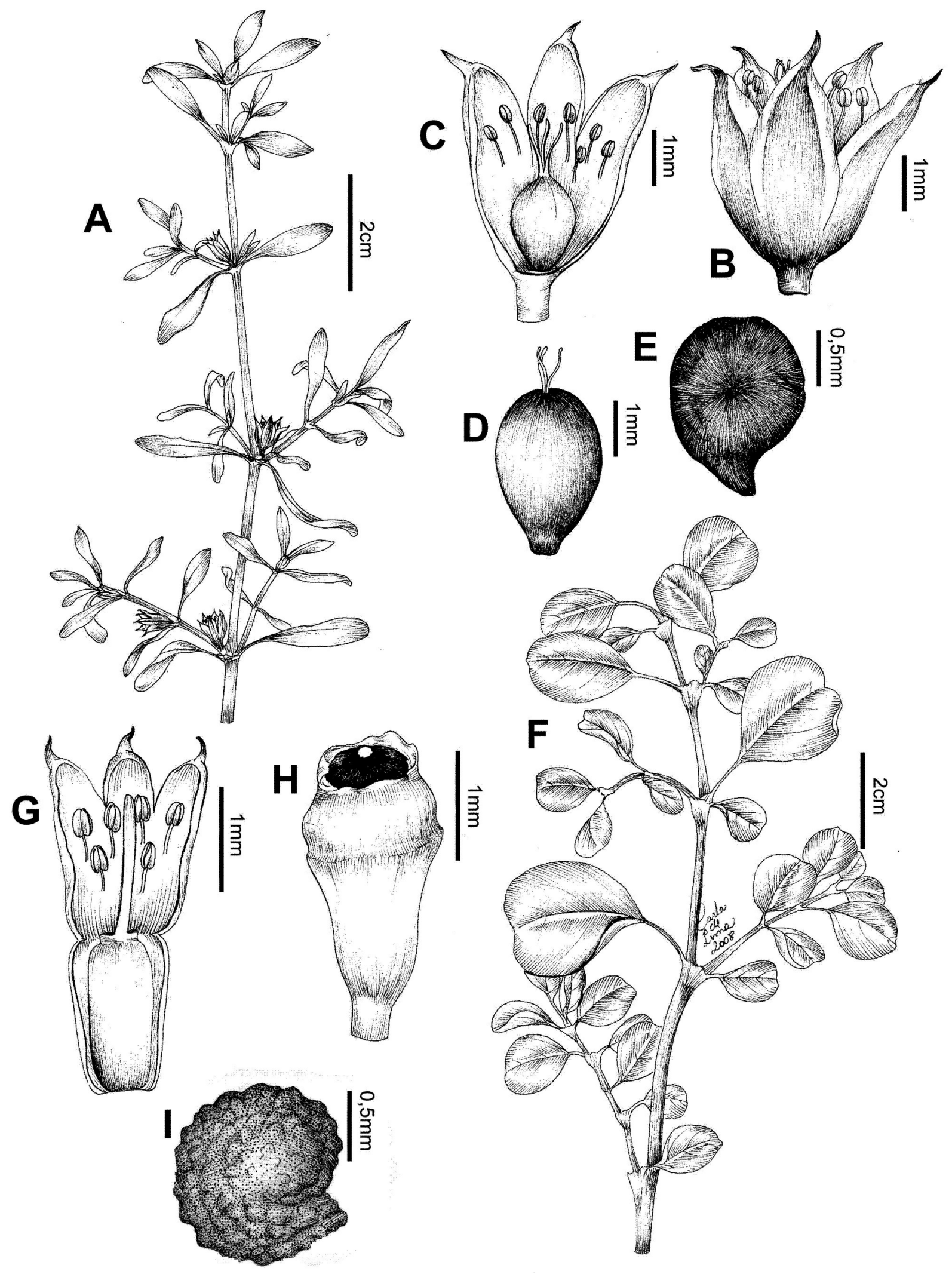

Figura 1. A-E. Sesuvium portulacastrum: A- hábito; B- flor fechada; C- flor aberta, corte longitudinal; D- fruto; E- semente (Carneiro-Torres 416). FI. Trianthema portulacastrum: F- hábito; G- flor, corte longitudinal; H- fruto; I- semente (Oliveira 135). 


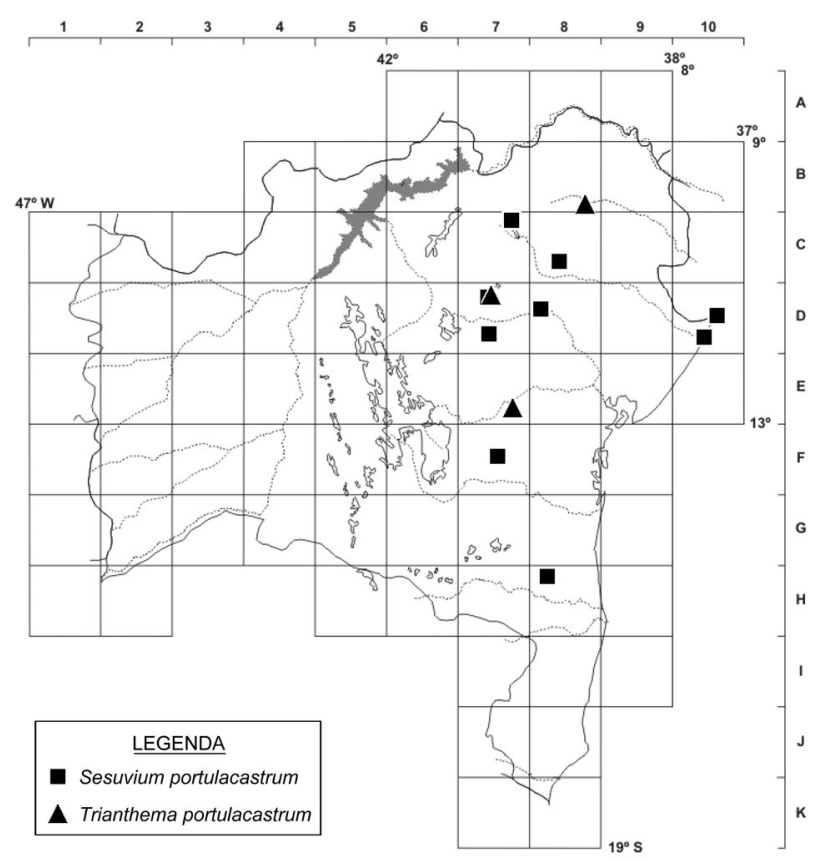

Figura 2. Mapa de distribuição de Sesuvium portulacastrum e Trianthema portulacastrum no estado da Bahia.

É a espécie com maior distribuição do gênero, ocorrendo principalmente em ambientes salinos de quase todas as regiões tropicais e subtropicais do globo (Bittrich 2002). C7, C8, D7, D8, D10, F7, H8: caatinga arbustiva, borda de floresta, dunas, vegetação secundária e cerrado. Floresce e frutifica de janeiro a outubro.

Material selecionado - Cachoeira, $18^{\circ} 39^{\prime} \mathrm{S}, 39^{\circ} 05^{\prime} \mathrm{W}$, fev. 1981, Grupo Pedra do Cavalo 1106 (HUEFS); Conde, 11\%44'80'S, 39³0'97'W, jan. 2003, N.G. Jesus et al. 1663 (HUEFS, HUNEB); Itaberaba, $12^{\circ} 30^{\prime} \mathrm{S}, 40^{\circ} 20^{\prime} \mathrm{W}$, maio 1985, A.P. Araújo 431 (ALCB, HRB); Itaju do Colônia, $15^{\circ} 08^{\prime} 34^{\prime \prime} \mathrm{S}, 39^{\circ} 43$ '26"W, fev. 2001, J.G. Jardim \& F. Juchum 3176 (HUEFS); Itiúba, 1040’25”S, 39³3'41"W, fev. 2000, A.M. Giulietti \& R.M. Harley 1826

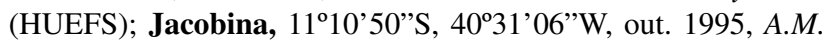

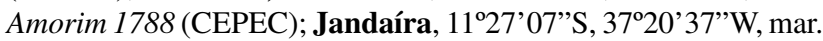
2003, L.M. Barbosa 1 (HUEFS); Jaraguari, 1006'01"S, $40^{\circ} 13^{\prime} 45^{\prime \prime} \mathrm{W}$, jul. 2005, D.S. Carneiro-Torres et al. 416 (HUEFS); Maracás, $13^{\circ} 26^{\prime} 27^{\prime}$ 'S, 40²5'51'W, jun. 1993, L.P. Queiroz \&

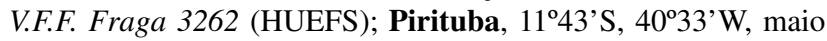
1980, L.R. Noblick 1878 (HRB, HUEFS); Riachão de Jacuípe, 11²2'S, 3949'W, jul. 1985, L.R. Noblick 4118 (HUEFS).

Comumente confundida com representantes de Portulaca L. (Portulacaceae), devido ao fruto do tipo pixídio, mas pode ser diferenciada pelas folhas opostas sem tricomas axilares (Bittrich 2002).

\section{Trianthema L.}

Ervas anuais ou perenes. Folhas opostas, suculentas, glabras. Flores bissexuadas, hipóginas ou epíginas, solitárias, sésseis ou pediceladas, bractéolas 2; sépalas 3-5, internamente róseas, amarelas ou esbranquiçadas, margens membranáceas, apêndice unifacial subapical abaxial; estames 5 a numerosos, estaminódios ausentes; ovário ínfero ou semiínfero, lóculos do ovário e estiletes 1-10, óvulos numerosos por lóculo, placentação apical. Fruto noz; sementes 1 a muitas, pretas, sem arilo.

O gênero inclui 20 espécies, com centro de diversidade na Austrália (Short 2011). No Brasil, ocorre apenas uma espécie (Zappi 2010).

2.1. Trianthema portulacastrum L., Sp. Pl.: 223. 1753.

Figuras $1 \mathrm{~F}-\mathrm{I}$ e 2.

Ervas perenes, glabras, prostradas, ramos quadrangulares em seção transversal, canaliculados. Folhas, obovadas ou romboidais, pecíolo 4-7 mm compr., glabro, lâmina 1-4,5 ×0,4-2,5 cm, ápice acuminado ou obtuso, base alargada formando uma bainha hialina, margem reta, ambas as faces glabras, concolor, cartácea, venação eucamptódroma Flores sésseis, bractéolas ca. $2 \mathrm{~mm}$ compr., membranáceas, triangulares, ápice agudo, base truncada, margem reta; sépalas 5, 4-4,5 mm compr., persistentes, cuculadas, internamente róseas ou esbranquiçadas, lilás, margens membranáceas, apêndice linear, 0,7-0,8 mm compr., agudo; estames 9-12, adnatos às sépalas, estaminódios ausentes, filetes $0,8-1 \mathrm{~mm}$ compr., anteras ca. 0,5 $\mathrm{mm}$ compr.; ovário oblongo, ca. 1,5 mm compr., glabro, lóculo 1, óvulos vários por lóculo, estilete 1 , ca. 2 mm compr., estigma truncado. Noz ca. $2 \times 2 \mathrm{~mm}$ compr., oblonga, glabra; sementes ca. 16, virguliformes, pretas, sem arilo, superfície verrucosa.

Pantropical, com registros de ocorrência para África, Ásia, Austrália, América Central e do Sul (Hartmann 1993; Zappi 2010; Short 2011). B8, D7, E7: caatinga e hábitats ruderais. Floresce e frutifica de janeiro a fevereiro.

Material selecionado - Canudos, 09 53'47'S, 3901'47' W, fev. 2004, R.M. Harley \& E.B. Miranda 54903 (HUEFS, K); Iaçu, 12'46'11'S, 40¹2'36”W, fev. 1997, A.M. Giulietti et al. 5485 (ALCB, CEPEC, HRB, HUEFS); Jacobina, 11 ${ }^{\circ} 10^{\prime} 50^{\prime \prime} \mathrm{S}$, 40³1'06'W, jan. 1999, M.V.M. Oliveira 135 (HUEFS).

\section{Agradecimentos}

Aos curadores dos herbários visitados, pela disponibilidade de material. À Carla de Lima pelas ilustrações. Ao Conselho Nacional de Desenvolvimento Científico e Tecnológico (CNPq), pela bolsa de doutorado concedida a LCPL, e de Produtividade em Pesquisa concedidas a AMG (PQ1-A) e RPO (PQ2). Ao CNPq e à FAPESB pelo financiamento do projeto Flora da Bahia (FAPESB APR 162/2007; CNPq Proc. 562278/2010-9 e 483909/2012). 


\section{REFERÊNCIAS}

Bittrich V. 2002. Aizoaceae In: M.G.L Wanderley, G. Shepherd \& A.M. Giulietti (eds), Flora Fanerogâmica do Estado de São Paulo. Vol. 2. Hucitec, São Paulo, p. 9-10.

Bittrich V. \& Hartmann H.E.K. 1989. The Aizoaceae - a new approach. Botanical Journal of the Linnean Society 97: 239254.

Hartmann H.E.K. 1993. Aizoaceae In: K. Kubitzki (ed.), The Families and Genera of Vascular Plants - Magnoliid, Hamamelid, Caryophyllidfamilies. Vol. 2. Springer, New York, p. 37-69.

Short, P.S. 2011. Aizoaceae. In: P.S. Short \& I.D. Cowie (eds),
Flora of the Darwin Region. Vol. 1. Dept. of Natural Resources, Environment, the Arts and Sport, Northern Territory, p. 1-4.

Souza V.C. \& Lorenzi H. 2005. Aizoaceae In: Botânica Sistemática: guia ilustrado para identificação das famílias de angiospermas da flora brasileira, baseado em APG II. Instituto Plantarum, Nova Odessa, p. 224.

Zappi, D. 2010. Aizoaceae. In: Lista de Espécies da Flora do Brasil. Jardim Botânico do Rio de Janeiro. Disponível em http:// floradobrasil.jbrj.gov.br/2010/FB000038; acessado em 7 Mar 2010 .

\section{Lista de Exsicatas}

Amorim, A.M. 1788 (1.1); Araújo, A.P. 431(1.1); Barbosa, L.M. 1 (1.1); Carneiro-Torres, D.S. 416 (1.1); Giulietti, A.M. 1753 (2.1), 1826, 3395 (1.1), 5485 (2.1); Grupo Pedra do Cavalo 1106 (1.1); Harley, R.M. 54903 (2.1); Jar- dim, J.G. 3176 (1.1); Jesus, N.G. 1663 (1.1); Melo, E. 2997 (1.1); Noblick, L.R. 1878, 4118 (1.1); Oliveira, M.V.M. 135 (2.1); Queiroz, L.P. 3262 (1.1). 